\title{
Prevalence and Factors Associated with Hypertension among Anti-Retroviral Therapy Patients Aged 15 Years and above in Makonde District, Zimbabwe, 2012: An Analytic Cross Sectional Study
}

\author{
Blessing Ruwimbo Mutede1, Tapiwa Magure², Notion Tafara Gombe¹, Donewell Bangure ${ }^{1 *}$ \\ Mufuta Tshimanga ${ }^{1}$, More Mungati ${ }^{1}$ \\ ${ }^{1}$ Department of Community Medicine, University of Zimbabwe, Harare, Zimbabwe \\ ${ }^{2}$ National AIDS Council, Zimbabwe, Harare, Zimbabwe \\ Email: ${ }^{*}$ bangured@yahoo.com
}

Received 11 June 2015; accepted 25 September 2015; published 28 September 2015

Copyright (C) 2015 by authors and Scientific Research Publishing Inc.

This work is licensed under the Creative Commons Attribution International License (CC BY).

http://creativecommons.org/licenses/by/4.0/

(c) (i) Open Access

\section{Abstract}

Background: Anti-retroviral therapy (ART) has reduced morbidity and mortality among HIV-infected individuals over the last years. The increase in survival of HIV patients has contributed to the emergence of other chronic conditions in these individuals, such as hypertension, renal, and cardiovascular disease. Hypertension and HIV infection are both mostly asymptomatic but can lead to fatal and disabling illness. Hypertension among HIV-infected individuals, although not completely elucidated, may be explained by the aging of population, the effect of HIV on vascular tone anti-retroviral therapy and traditional risk factors such as weight gain, smoking, dyslipidemia, and drug abuse. The factors associated with hypertension among ART patients in a predominantly rural setting were studied in this paper. Methods: We conducted an analytical cross sectional study at 13 health facilities in Makonde District a rural district in Mashonaland West Province of Zimbabwe where we systematically selected 393 of 400 ART patients aged 15 years and above. Structured interviewer administered questionnaires were used to collect data on demographic characteristics. Written and informed consent was sought and obtained from all study participants. We obtained parental consent followed by assent from participants younger than 16 years. All enrolled patients had physical measurements done. Chi square test and stratified \& logistic regression analysis were done using Epi info version 3.5.1. All calculations were done at $95 \%$ confidence interval. Results: Results from 393 participants were analysed. The prevalence and

*Corresponding author.

How to cite this paper: Mutede, B.R., et al. (2015) Prevalence and Factors Associated with Hypertension among Anti-Retroviral Therapy Patients Aged 15 Years and above in Makonde District, Zimbabwe, 2012: An Analytic Cross Sectional Study. World Journal of Cardiovascular Diseases, 5, 266-277. http://dx.doi.org/10.4236/wjcd.2015.59030 
awareness of hypertension were $34.9 \%$ and $30 \%$ respectively. Only $9.6 \%$ were taking medication. Independent risk factors were duration of ART > 2 years (POR 2.23; 95\%CI: 1.08; 4.61), waist to hip ratio (women) > 0.85 (POR 3.45; 95\%CI: 1.60; 5.88), B.M.I > 25 (POR 2.18; 95\%CI: 1.40; 3.8). Protective factors were: Symptomatic HIV disease (POR 0.36; 95\%CI: 0.14; 0.97) and being informally employed (POR 0.67; 95\%CI: 0.43; 0.96). General risk factors were smoking (POR 5.06; 95\%CI: 2.20; 11.60), sedentary recreation (POR 3.16; 95\%CI: 1.69; 5.85) and high salt intake (POR 2.67; 95\%CI: 1.56; 4.59). Conclusions: Hypertension is common among ART clients although it is not routinely screened for in ART care settings in Makonde. Common modifiable risk factors are contributing to the burden of hypertension in Makonde District. Health service providers should routinely screen for hypertension and promote healthy lifestyles among ART clients in Makonde.

\section{Keywords}

\section{ART Patients, Prevalence, Hypertension, Makonde Zimbabwe}

\section{Background}

Anti-retroviral therapy (ART) has reduced morbidity and mortality among HIV-infected individuals over the last years. The increase in survival of HIV patients has contributed to the emergence of other chronic conditions in these individuals, such as hypertension, renal, and cardiovascular disease. Hypertension and HIV infection are both mostly asymptomatic but can lead to fatal and disabling illness.

Hypertension, a disease characterized by sustained elevation of arterial blood pressure, occurs in all geographical areas of the world [1]. It is more common in developed countries than in economically developing countries with a prevalence of $37.3 \%$ and $22.9 \%$ respectively [2].

Globally, raised blood pressure causes 7.5 million deaths per annum which translate to about $12.8 \%$ of all deaths [2]. Cardiovascular diseases which are responsible for 30\% of all deaths worldwide are due to chronic and uncontrolled or poorly controlled hypertension [2]. Although a leading cause of morbidity and mortality in the developed countries, it is overshadowed by the burden of communicable conditions in the developing world. Little is known about hypertension in the HIV-infected population [2] [6].

Human Immunodeficiency Virus (HIV) infection in human beings causes a chronic disease characterized by progressive loss of immunological function, consequent opportunistic infections and neoplasia leading to death [1]. About 35.3 million people were living with HIV in the world and about $68 \%$ of these live in Sub Saharan Africa. [5] Ninety percent of the infected are adults, where women constitute 52\% [5] [11] [12]. The peak for HIV infection which occurs between the 25 to 49 year age group leads that of hypertension which occurs at the more advanced age groups greater than 45 years [2]-[5].

HIV has become a manageable chronic condition through the use of antiretroviral drugs. Although HIV treatment may predispose to hypertension, there is little data about its effects in uncontrolled settings at population level; particularly in Sub Saharan Africa where the bulk of these drugs are used. Few and conflicting studies have investigated the behaviour of blood pressure in HIV patients [14]-[17].

Hypertension and HIV are common in Zimbabwe and often occur in the same patient. Unfortunately programming for the management of these conditions is done vertically with very little scope for linkages and interaction. The STEPwise survey done in Zimbabwe in 2005 found the prevalence of hypertension to be 27\% [7]. The latest demographic and health survey done in 2011 revealed a prevalence of HIV in Zimbabwe of 15\% between the ages of 15 to 49 years [8].

Hypertension and HIV account for approximately $25 \%$ and $45 \%$ of all chronic outpatient visits respectively [3] [12]. Combined they are the biggest cause of disabilities and attendances at medical rehabilitation units. By the end of 2012 about 565675 (77\%) (69\%) HIV infected people were on Antiretroviral Therapy (ART) in Zimbabwe [11] [12]. The drugs used in the National ART program are, Stavudine or Zidovudine with Lamivudine and Nevirapine or Efavirenz in the first line. Tenofovir was recently introduced to the first line replacing Stavudine. Ritonavir boosted Lopinavir (Kaletra or Alluvia) is one of the drugs used for second line ART. More than $80 \%$ of ART clients are still on Stavudine based regimens [12]. 
Makonde District, one of the 8 districts in Mashonaland West Province in Zimbabwe, had a population of around 232,560 people who are attended to in 38 health facilities including a tertiary hospital [13]. ART clinics in Makonde District are run vertically separate from routine OPD activities where chronic diseases are managed. Holistic care, though emphasised is not practised in ART sites. Patients are referred to other departments, other health service centres or given different dates for attention of other ailments. By the end of 2011, 9293 people were on ART in Makonde District, of which 63.2\% were females, 92.3\% were above 15 years and 81 clients (1\%) were on second line regimens. Approximately $85 \%$ of these clients are on stavudine based regimens [13]. The majority of these clients ( $>75 \%$ ) had well controlled HIV disease. However approximately $8 \%$ of these clients suffered a stroke at some point resulting in permanent disability. A review of statistics for January to March 2012 showed that $32 \%$ of the 324 patients aged 15 years or more, seen for management of both acute and old cerebrovascular accidents in the physiotherapy department at Chinhoyi Hospital alone, were on ART. This is higher than the estimated district HIV positivity rate of only 14\%. Twenty six (26) clients had experienced strokes for the first time over this period and had no known risk factors for cardiovascular disease.

We hypothesized that hypertension was common in Makonde District and that it was associated with antiretroviral therapy. No study has been done in Zimbabwe on hypertension among ART clients.

\section{Methods}

An Analytic Cross Sectional Study was conducted among ART clients aged 15 years and above attending 13 different ART clinics in Makonde district. A sample size of 405 ART clients was required for this study after correcting for $5 \%$ attrition.

We included ART clients who were aged 15 years and older, who resided in Makonde and had been on ART for at least 6 months. Visiting clients, those who stayed in the district for less than 6 months on ART, ill clients and confirmed secondary hypertensives were excluded.

Three ART initiating sites, Chinhoyi Provincial, Makonde Christian and St Rupert's Hospitals, were purposively selected for this study. Ten follow up sites were randomly selected from the using the lottery method by assigning the 35 health facilities with numbers from 1 to 35 and randomly picking similarly numbered pieces of paper from a hat raised higher than the head of the investigator who was picking the numbers. Quota sampling reflecting volume of clients was done for each chosen centre such that the busiest centre Chinhoyi Hospital had the highest number of clients (203) and the follow up clinics 4 clients each.

Clients were systematically selected from the daily OI/ART attendance register for each centre. The sampling interval was obtained by dividing the total number of clients turning up on a given day by the number of respondents calculated for that centre for that day. The first client was chosen randomly by picking the client whose number corresponded to the first digit appearing on a random number generated by a scientific calculator. Records of selected respondents were reviewed to measure variables such as date of HIV diagnosis, duration on ART and ART regimen, stage of HIV disease and co-morbidity.

Structured interviewer administered questionnaires were used to collect data on the following variables: age, sex, level of education, occupation, level of income, alcohol use, tobacco use, concomitant use of herbs and level of activity. Direct measurements were done to collect data on the following variables: waist circumference $(\mathrm{cm})$, hip circumference $(\mathrm{cm})$, weight $(\mathrm{kg})$ and height $(\mathrm{cm})$ The waist to hip ratio (W.H.R) and Body Mass Index (B.M.I) were computed from these variables and classified using World Health Organization (WHO) standards (Table 1, Table 2).

Blood pressure, the main outcome variable was measured indirectly and blood pressures classified according to the Seventh Joint National Committee on Hypertension (JNC VII) classification of blood pressures (Table 3)

Table 1. Classification of waist to hip ratio.

\begin{tabular}{ccc} 
& \multicolumn{2}{c}{ Waist to Hip Ratio Chart } \\
\hline Male & Female & Health Risk Based Solely on WHR \\
\hline 0.95 or below & 0.80 or below & Low Risk \\
0.96 to 1.0 & 0.81 to 0.85 & Moderate Risk \\
$1.0+$ & $0.85^{+}$ & High Risk \\
\hline
\end{tabular}


Table 2. Body mass index classification.

\begin{tabular}{ccc}
\hline Classification & \multicolumn{2}{c}{ BMI $\left(\mathbf{k g} / \mathbf{m}^{2}\right)$} \\
\hline Underweight & Principal Cut-Off Points & Additional Cut-Off Points \\
\hline Normal Range & $<18.50$ & $<18.50$ \\
Overweight & $18.50-24.99$ & $18.50-22.99$ \\
Obese & $\geq 25.00$ & $23.00-24.99$ \\
& $\geq 30.00$ & $\geq 25.00$ \\
\hline
\end{tabular}

Table 3. Classification of blood pressures [9].

\begin{tabular}{ccc}
\hline Category & SBP $(\mathbf{m m} \mathbf{H g})$ & DBP $(\mathbf{m m} \mathbf{H g})$ \\
Normal & $<120$ & $<80$ \\
Pre Hypertension & $120-139$ & or $80-89$ \\
Stage 1 Hypertension & $140-159$ & or $90-99$ \\
Stage 2 & $>159$ & or $>99$ \\
\hline
\end{tabular}

[5]. Blood pressure was measured using portable desk aneroid sphygmomanometers. Three different machines were used at different data collection points. These were calibrated against a standard desk mercury sphygmomanometer-C E 0483.

The procedures used were adapted from the Zimbabwe STEPwise survey of 2005 (annex 2). Data collection tools and methods were pretested at Chinhoyi Clinic and revised accordingly.

Prevalence, frequencies, proportions were calculated using Epi info ver.3.5.1 (CDC, Atlanta, 2008) and Microsoft Excel $^{\circledR} 2007$ was used to generate graphs. A double entry system was used to safe guard data quality. These were tested for statistical differences between comparison groups at the $5 \%$ significance level by constructing 95\% confidence intervals around the point estimates and assessing these for overlap. $\mathrm{T}$ test and Chi square based P-values were also used to confirm the significance of the observed differences.

Bivariate analysis was done by comparing the hypertensive ART clients to those who were not through construction of series of $2 \times 2$ tables cross tabulating the outcome variable "Hypertension present?" Against different exposure variables and determining point estimates for the respective prevalence odds ratios (P.O.R.). These estimates were tested for statistical significance at the $5 \%$ significance level. Since controlling for any confounder and effect modifiers was not possible with this study design, stratified analysis calculating the prevalence odds ratios was done to control for confounding and assess for effect modification.

Forward step wise logistic regression was done to control for confounding by selecting variables which had shown associations with p-values that were 0.25 and less and building these into a model putting one variable at time.

Written and informed consent was sought and obtained from all study participants. For participants younger than 16 years we first sought parental consent followed by assent from the participants. Anonymity of study participants was guaranteed by appropriately coding all variables which could lead to identification of individual respondents. Data security was guaranteed by locking up all questionnaires in lockable cupboard. Untreated and inappropriately managed hypertensives were referred for appropriate care. Ethical approval was obtained from the Joint Research and Ethic Committee of Parirenyatwa Hospital (JREC/213/12).

Permission to carry out the study was sought and obtained from the Health Studies Office-Ministry of Health and Child Welfare, Provincial Medical Director for Mashonaland West and the Medical Research Council of Zimbabwe (MRCZ).

\section{Results}

\subsection{Introduction}

We interviewed 400 ART clients. Seven questionnaires were excluded from the analysis due to absence of blood pressure record. Three hundred and ninety three (97\%) completed questionnaire were analysed. 


\subsection{Socio-Demographic Characteristics of Respondents}

Most of the respondents (52.4\%) were between 30 to 45 years of age. More women (56.6\%) than men were enrolled into this study. Most of the respondents (71.3\%) were educated beyond primary level. Fifty eight percent were employed in the informal sector and 59.5\% earning incomes less than 100 USD per month (Table 4).

\subsection{Clinical and Behavioural Factors}

Twenty nine percent of men and 36.6\% of women were overweight or obese. There was no significant difference between the sexes $(p=0.16)$. The majority of women $(90.4 \%)$ had waist to hip ratios that were in the high risk category whereas most men (66.7\%) were in the medium risk category.

Table 4. Demographic characteristics of sampled ART clients aged 15 years and above in Makonde District, Zimbabwe 2012.

\begin{tabular}{|c|c|c|c|}
\hline \multirow{2}{*}{ Socio-Demographic Characteristics } & \multicolumn{2}{|c|}{ Total $(n=393)$} & \multirow{2}{*}{ p-Value } \\
\hline & No. Hypertensive (137) & No. Not Hypertensive (256) & \\
\hline \multicolumn{4}{|l|}{ Age Group (Years) } \\
\hline $15-30$ & 32 & 66 & 0.00 \\
\hline $31-45$ & 58 & 148 & \\
\hline $46-60$ & 35 & 29 & \\
\hline $61-75$ & 7 & 5 & \\
\hline \multicolumn{4}{|l|}{ Sex } \\
\hline Female & 81 & 142 & 0.49 \\
\hline Male & 56 & 114 & \\
\hline \multicolumn{4}{|l|}{ Marital Status } \\
\hline Single & 14 & 49 & 0.01 \\
\hline Married & 73 & 149 & \\
\hline Divorced & 8 & 13 & \\
\hline Widowed & 26 & 27 & \\
\hline Separated & 8 & 14 & \\
\hline Cohabiting & 8 & 4 & \\
\hline \multicolumn{4}{|l|}{ Level of Education } \\
\hline Primary and below & 40 & 73 & 0.04 \\
\hline Secondary & 81 & 172 & \\
\hline Tertiary & 16 & 11 & \\
\hline \multicolumn{4}{|l|}{ Occupation } \\
\hline Informal & 71 & 155 & 0.08 \\
\hline Formal Skilled & 38 & 33 & \\
\hline Not Employed & 26 & 44 & \\
\hline Student & 2 & 5 & \\
\hline \multicolumn{4}{|l|}{ Income Level } \\
\hline$<100$ & 80 & 154 & 0.36 \\
\hline $100-350$ & 34 & 74 & \\
\hline $350-500$ & 0 & 1 & \\
\hline$>500$ & 8 & 7 & \\
\hline
\end{tabular}


The Mean Systolic Blood Pressure was $123 \pm 19$ mmHg. The Mean Diastolic Blood Pressure was $81 \pm 14$ mmHg.

Most (72.3\%) of the clients had been diagnosed HIV positive within 5 years prior to the interview. The median year of diagnosis was 2010 (IQR: 2005 - 2011) and most of the respondents (58\%) were in WHO Clinical Stage III disease at diagnosis.

Prevalence of alcohol consumption, routinely adding salt to served food (a proxy for high salt intake) and physical inactivity was above $50 \%$ in both men and women. Significantly more men (18.8\%) than females (5\%) reported smoking (POR 3.9; 95\%CI: 1.8; 8.9). The reported median number of days in a week over which respondents reported being physically active was 3 days (IQR: 1 - 5). On any given day the physical exertion took 3 hours (IQR: 2 - 10).

\subsection{Prevalence of Hypertension}

The crude prevalence of hypertension from this study was 34.9\% (30.2; 39.8). The prevalence on hypertension was higher among women (36.8\%) as compared to men (32.9\%). This was, however, not significant (POR 1.16; 95\%CI: 0.76; 1.77). The distribution of clients in the different blood pressure categories is shown in Table 5. Most of the respondents $79.4 \%$ (75.0; 83.3) had not been diagnosed with hypertension prior to the study and only 5.3\% (3.6; 8.3) were hypertensive before they commenced ART. The prevalence of hypertension was highest among clients followed up at Chinhoyi Provincial hospital 43.3\% (38.2; 49.5) followed by those attending Makonde Christian Hospital 31.6\% (25.7; 37.5). It was least among clients from St Rupert’s at 26.9 (20.8; 33.4).

The prevalence of hypertension was higher among those ART clients who were female $36.5 \%$ (30.1; 43.2), those who were single $37.4 \%$ (30.2; 45.1), those who had attained tertiary education $59.3 \%(38.8 ; 72.6)$ and those who were formally employed $41.2 \%$ (31.3; 51.7). It was also higher among those who had incomes above 350 USD $46.0 \%$ (31.8; 60.7).

The prevalence of hypertension in clients on Zidovudine and Stavudine containing regimens was $56.4 \%$ and $40 \%$ respectively showing a rise with increased duration of exposure to these medicines. This trend was not significantly different between sexes $(\mathrm{p}=0.87)$.

\subsection{Factors Associated with Hypertension}

Significant life style related risk factors for hypertension among ART clients were, smoking, (POR5.24; 95\%CI: 2.63 - 10.44), routinely adding salt to served food (POR 3.52; 95\%CI: 2.28 - 5.46), B.M.I above $25 \mathrm{~kg} / \mathrm{m}^{2}$ (POR 2.22; 95\%CI: 1.43 - 3.43), and a waist to hip ratio above 0.85 for women (POR 2.51; 95\%CI: 1.01 - 6.98) (Table 6).

Having asymptomatic disease at HIV diagnosis (POR 2.88; 95\%CI: 1.33 - 6.23), being on a Stavudine or Zidovudine containing regimen (POR 2.00; 95\%CI: 1.31 - 3.09) and being on ART for more than 24 months (POR 3.99; 95\%CI: 2.23 - 7.13), were significantly associated with hypertension in this study (Table 6).

\subsection{Independent Risk Factors for Hypertension}

General significant independent risk factors for hypertension in this study were being female (aOR 2.38; 95\%CI: 1.31 - 4.34), being older than 45 years (aOR 4.61; 95\%CI: 2.03 - 10.48), smoking (aOR 5.24; 95\%CI: 2.63 10.44), adding salt to served food (aOR 2.67; 95\%CI: 1.56 - 4.59), physical inactivity (POR 3.16; 95\%CI: 1.69 5.85), B.M.I > 25 (POR 2.18; 95\%CI: 1.40 - 3.8). Working in informal environment was protective (aOR 0.49;

Table 5. Classification of ART clients aged 15 years and above in Makonde District by blood pressure values, 2012.

\begin{tabular}{|c|c|c|c|}
\hline Blood Pressure Classification & Males (95 C.I.) $n_{1}=170$ & Women (95\% C.I.) $n_{2}=223$ & Crude (95\% C.I.) $N=393$ \\
\hline Normotensive & $57.1(49.3 ; 64.6)$ & $52.0(45.0 ; 60.3)$ & $54.1(49.0 ; 59.1)$ \\
\hline Pre-Hypertensive & $10.6(6.4 ; 16.2)$ & $11.2(7.4 ; 16.1)$ & $11.0(08.1 ; 14.6)$ \\
\hline Stage I Hypertension & $25.9(19.5 ; 33.1)$ & $27.4(21.6 ; 33.7)$ & $26.8(22.5 ; 31.5)$ \\
\hline Stage II Hypertension & $6.5(3.3 ; 11.3)$ & $9.4(5.9 ; 14.0)$ & $8.2(05.7 ; 11.4)$ \\
\hline
\end{tabular}


95\%CI: 0.25 - 0.96) (Table 6). Significant independent disease and treatment related risk factors were duration on ART of more than 2 years (aOR 2.23; 95\%CI: 1.08 - 4.61) and having W.H.R greater than 0.85 in females (aOR 3.45; 95\%CI: 1.60 - 5.88). Having symptomatic HIV disease was protective (aOR 0.36; 95\%CI: 0.14 0.97) (Tables 7-9).

Table 6. Lifestyle related factors associated with hypertension among ART clients aged 15 years and above in Makonde District, Zimbabwe, 2012.

\begin{tabular}{|c|c|c|c|c|c|}
\hline \multirow{2}{*}{ Variable } & \multirow{2}{*}{ Category } & \multicolumn{2}{|c|}{ Hypertension Present? } & \multirow{2}{*}{ P.O.R } & \multirow{2}{*}{ 95\% C.I. } \\
\hline & & Yes & No & & \\
\hline \multirow[b]{2}{*}{ Smokes } & Yes & 30 & 13 & \multirow[b]{2}{*}{5.24} & \multirow{2}{*}{$(2.63 ; 10.44)$} \\
\hline & No & 107 & 243 & & \\
\hline \multirow{2}{*}{ Consumes Alcohol } & Yes & 58 & 75 & \multirow{2}{*}{1.78} & \multirow{2}{*}{$(1.15 ; 2.73)$} \\
\hline & No & 79 & 181 & & \\
\hline \multirow{2}{*}{ Routinely Adds Salt to Served Food } & Yes & 91 & 92 & \multirow{2}{*}{3.52} & \multirow{2}{*}{$(2.28 ; 5.46)$} \\
\hline & No & 46 & 164 & & \\
\hline \multirow[b]{2}{*}{ Works While Seated } & Yes & 58 & 74 & \multirow[b]{2}{*}{3.52} & \multirow[b]{2}{*}{$(1.15 ; 3.33)$} \\
\hline & No & 77 & 175 & & \\
\hline \multirow{3}{*}{ Recreation While Seated } & Yes & 51 & 38 & \multirow{3}{*}{3.36} & \multirow{3}{*}{$(2.06 ; 5.50)$} \\
\hline & No & 83 & 208 & & \\
\hline & $>5$ years & 83 & 105 & & \\
\hline \multirow{2}{*}{ B.M.I $>25 \mathrm{~kg} / \mathrm{m}^{2}$} & Yes & 61 & 68 & \multirow[b]{2}{*}{2.22} & \multirow[b]{2}{*}{$(1.43 ; 3.43)$} \\
\hline & No & 76 & 188 & & \\
\hline \multirow{2}{*}{ Waist to Hip Ratio > 0.96 (Men) } & Yes & 40 & 72 & \multirow{2}{*}{1.37} & \multirow{2}{*}{$(0.67 ; 2.80)$} \\
\hline & No & 15 & 37 & & \\
\hline Waist to Hip Ratio > 0.85 (Women) & Yes & 76 & 121 & 2.51 & $(1.01 ; 6.98)$ \\
\hline
\end{tabular}

Table 7. Disease and treatment related factors associated with hypertension among ART clients aged 15 years and above in Makonde District, 2012.

\begin{tabular}{|c|c|c|c|c|c|}
\hline \multirow{2}{*}{ Variable } & \multirow{2}{*}{ Category } & \multicolumn{2}{|c|}{ Hypertension Present? } & \multirow{2}{*}{ P.O.R } & \multirow{2}{*}{ 95\% C.I. } \\
\hline & & Yes & No & & \\
\hline \multirow[b]{2}{*}{ HIV Disease Stage at Diagnosis } & Asymptomatic & 17 & 12 & \multirow[b]{2}{*}{2.88} & \multirow[b]{2}{*}{$(1.33 ; 6.23)$} \\
\hline & Symptomatic & 120 & 244 & & \\
\hline \multirow[b]{2}{*}{ Time from HIV Diagnosis } & $<5$ Years & 54 & 151 & \multirow[b]{2}{*}{0.45} & \multirow[b]{2}{*}{$(0.30 ; 0.69)$} \\
\hline & $>5$ Years & 83 & 105 & & \\
\hline \multirow[b]{2}{*}{ Other co Morbidity } & Yes & 36 & 31 & \multirow[b]{2}{*}{2.69} & \multirow[b]{2}{*}{$(1.56 ; 4.63)$} \\
\hline & No & 85 & 197 & & \\
\hline \multirow[t]{2}{*}{ Type of Regimen } & D4T/AZT Containing & 76 & 98 & \multirow{2}{*}{2.00} & \multirow{2}{*}{$(1.31 ; 3.09)$} \\
\hline & TDF Containing & 56 & 145 & & \\
\hline \multirow[b]{2}{*}{ Duration of ART } & >24 Months & 37 & 22 & \multirow[b]{2}{*}{3.99} & \multirow[b]{2}{*}{$(2.23 ; 7.13)$} \\
\hline & $<24$ Months & 92 & 218 & & \\
\hline
\end{tabular}


Table 8. Independent factors associated with hypertension among ART clients aged 15 years and above in Makonde District, 2012.

\begin{tabular}{|c|c|c|c|c|}
\hline Variable & Crude Odds Ratio & (95\% C.I) & Adjusted Odds Ratio & (95\% C.I.) \\
\hline \multicolumn{5}{|c|}{ Socio Demographic } \\
\hline Being Female & 1.16 & $(0.76 ; 1.78)$ & 2.38 & $(1.31 ; 4.34)$ \\
\hline Age Greater than 45 Years & 3.41 & $(2.06 ; 5.65)$ & 4.61 & $(2.03 ; 10.48)$ \\
\hline Working in Informal Sector & 0.67 & $(0.43 ; 0.96)$ & 0.49 & $(0.25 ; 0.96)$ \\
\hline \multicolumn{5}{|c|}{ Life Style Related Factors } \\
\hline Alcohol Use & 1.78 & $(1.15 ; 2.73)$ & 1.29 & $(0.94 ; 2.33)$ \\
\hline Smoking & 5.24 & $(2.63 ; 10.44)$ & 5.06 & $(2.20 ; 11.66)$ \\
\hline Adding Salt to Served Food & 3.52 & $(2.28 ; 5.46)$ & 2.67 & $(1.56 ; 4.59)$ \\
\hline Not Being Active during Recreation & 3.36 & $(2.06 ; 5.50)$ & 3.16 & $(1.69 ; 5.85)$ \\
\hline B.M.I > 25 & 2.22 & $(1.43 ; 3.43)$ & 2.18 & $(1.40 ; 3.8)$ \\
\hline
\end{tabular}

Table 9. Independent disease and treatment related factors associated with hypertension among ART among ART Clients aged 15 years and above in Makonde District, 2012.

\begin{tabular}{ccccc}
\hline Variable & Crude Odds Ratio & $\mathbf{( 9 5 \% ~ C . I ) ~}$ & Adjusted Odds Ratio & $\mathbf{( 9 5 \% ~ C . I . ) ~}$ \\
\hline & Disease and Treatment & Related Factors & & \\
Having Symptomatic HIV Disease & 0.34 & $(0.16 ; 0.79)$ & 0.36 & $(0.14 ; 0.97)$ \\
Duration of ART > 2 Years & 3.99 & $(2.23 ; 7.13)$ & 2.23 & $(1.08 ; 4.61)$ \\
Being on D4T or AZT Regimens & 2.00 & $(1.31 ; 3.09)$ & 1.29 & $(0.74 ; 2.2)$ \\
W.H.R $>$ 0.85 (Females) & 2.51 & $(1.01 ; 6.98)$ & 3.45 & $(1.60 ; 5.88)$ \\
\hline
\end{tabular}

Of the $34.9 \%$ who were hypertensive, $20 \%$ were not aware they were hypertensive and only $9.9 \%$ were taking medication for their condition in the week prior to the interview. The proportion of respondents who had their blood pressure checked in the past year was $65.8 \%$ and only $33.7 \%$ had been given advice to address the modifiable risk factors for hypertension in their lives.

\section{Discussion}

The respondents interviewed in this study had a socio demographic profile similar to the profile of the general population, from which they were drawn as reported in the Zimbabwe Demographic and Health Survey of 2011 [9]. The treatment and disease related characteristics of the sampled clients were similar to those of ART clients in Zimbabwe as reported through national and local ART reports [11]-[13]. More women than men were interviewed; the modal age group of the sampled ART clients was 31 to 45 years and mostly first presented with stage 3 disease. Most were diagnosed with HIV after 2006. This suggests that a representative sample of ART clients in Makonde and in Zimbabwe was achieved in this study.

The crude prevalence of hypertension in this study was $34.9 \%(30.2 ; 39.8)$. This is comparable to findings from an American study by Gazzaruso et al. which similarly looked at hypertension among ART clients. They found a prevalence of hypertension of 34.2\% [28]. Although a direct comparison with the HIV negative population is not possible in this study, a survey done in 2005 in Zimbabwe using similar tools and methods showed a prevalence of hypertension in the general population of 28\% [7]. There was a high prevalence of modifiable risk factors for hypertension such as alcohol consumption, routinely adding salt to served food, physical inactivity at recreation and being overweight or obese among respondents in this study. The STEPwise survey done in Zimbabwe in 2005, had similar findings in the general population [7]. Symptomatic disease was protective. This could be an indication that once treated, ART clients have a similar hypertension risk profiles as the general 
population and hypertension should be routinely screened for during drug pick up and clinic reviews for HIV disease [23].

More females than men had waist to hip ratios in the high risk category. This is in keeping with several local studies which have shown higher prevalence of lipodystrophy in women on ART as compared to men [10] [21][25]. The usual syndrome has central lipohypertrophy and lipoatrophy of the limbs [10]. Consequently women in this study were more likely to be hypertensive compared to men. Similar findings were reported by Sattler et $a l$. in a case control study done between 2001 and 2010 [20]. This finding which is contrary to the general population where men carry a higher risk of hypertension than women is explained by the greater likelihood of dyslipidaemia in ART clients with lipodystrophy as compared to those without. Duration of ART more than 2 years was a risk factor for hypertension in this study. Similar findings have been reported by the MACS cohort study which ran from 1984 to 2003 and in an observational cohort analysis of a Senegalese ART cohort [18] [24]. ART regimens containing D4T or AZT were associated with higher likelihood of developing hypertension although statistical significance was lost after multivariate analysis. Several studies have described the hypertensive potential of nucleoside reverse transcriptase inhibitors due to their effect on lipid metabolism [14] [19] [20] [27]. Although the link between use of ART and dyslipidaemia can explain this observation, the increased survival and quality of life of PLHIV on ART and the attendant high prevalence of risk factors for hypertension such as obesity, recreational drug use and sedentary recreation seen in this study also play a significant role.

Having asymptomatic HIV infection at diagnosis was a risk factor for hypertension in this study. It can be explained, by different behavioural responses to illness between clients with symptomatic disease and those without. Patients who have experienced illness are motivated to adhere to treatment protocols, which include addressing all the modifiable risk factors for hypertension as compared to asymptomatic individuals.

Although the majority of hypertensive ART clients in this study were diagnosed after HIV diagnosis and subsequent ART, this in itself is not an indication of the hypertensive potential of ART. It may simply be due to increased opportunity for interacting with health personnel afforded to ART clients by sustained follow up for HIV care. This is a potential source of lead time bias in interpreting hypertension outcomes.

The management of hypertension by health providers in this study is suboptimal since up to $34.2 \%$ of respondents have not had their blood pressure checked in the past year despite their frequent interaction with health staff, consequently $30 \%$ of the hypertensive ART clients were not aware of their condition. This is similar to findings in a cross sectional study done in Tanzania in 2012-2013 where less than $25 \%$ of the respondents who included ART clients were aware of their hypertensive states [26]. This is further evidence of suboptimal health provider practices. An even lower percentage was actively taking medication at the time of the study and only a third had received some advice on preventing and managing hypertension. A pilot study done at a local secondary level facility in Nigeria concluded that integration of screening for cardiovascular diseases in ART clinic settings is feasible and essential, in order to improve the life expectancy of HIV-positive individuals [23].

Limitations in this survey include failure to conduct laboratory testing for clients to assess for diabetes mellitus, dyslipidaemias and renal impairment which are common risk factors for hypertension in ART clients.

Low numbers of participants below 18 years were enrolled due to the absence in most cases of a guardian to give consent.

\section{Conclusion}

Hypertension is common among ART Clients in Makonde and has the same general risk as those in the general population. Being on ART for more than two years was a risk factor for hypertension for clients on ART in this study. Asymptomatic HIV disease could be a risk factor for hypertension due to lowered risk perception among clients initiated on ART before falling sick among ART clients in this study. Health providers in this assessment are not routinely screening for hypertension among ART clients hence miss out on managing up to $70 \%$ of the hypertension in the ART populationin Makonde

\section{Recommendations}

There is need to put in place a system and resources to screen all ART clients for hypertension as they come to consume ART services. ART clients older than 45 years, women and those on ART for more than 2 years are special groups that require special emphasis.

Health talks given to ART clients at reviews must include the benefits of exercise during recreation; restric- 
tion of salt intake, dietary management of weight and. Removal of salt from the table is a good starting point for managing the intake of salt at the household level.

The relationship between hypertension and being on ART for more than 2 years, ART regimen and sex (ART clients) needs to be further evaluated using more powerful study designs such as a cohort studies with the inclusion of biochemical sampling.

There is need to develop a strategy of integrating chronic non communicable disease management and prevention into HIV programming since existing HIV care program affords a platform for interacting with clients whose susceptibilities have been enunciated by this study in Makonde.

\section{Competing Interests}

The authors declare that they have no competing interests, both financial and non-financial.

\section{Authors' Contributions}

B.M.: conception, design, acquisition, analysis and interpretation of data and drafting the manuscript. T.M.: conception, design, acquisition, analysis and interpretation of data and drafting the manuscript. N.G., D.B., M.M.: conception, design, data collection, analysis, interpretation and reviewing of several drafts of the manuscript for important intellectual content. M.T. had oversight of all stages of the research and critically reviewed the final draft for important intellectual content. All authors read and approved the final manuscript.

\section{Acknowledgements}

This research was supported by the following people and organisations both intellectually and financially: CDC Atlanta: Health Studies Office, MoHCC; Provincial Medical Director, Mashonaland West Province; District Health Executive, Makonde District; Department of Community Medicine; Zimbabwe Field Epidemiology Training Program staff.

\section{References}

[1] Kasper, D.L., Braunwald, E., Hauser, S., Longo, D., Jameson, J.L. and Fauci, A.S. (2006) Harrisons Principles of Internal Medicine. 16th Edition, McGraw Hill Medical Publishing Division, New York, 752-954.

[2] Kearney, P.M., Whelton, M., Reynolds, K., Muntner, P., Whelton, P.K. and He, J. (2005) Global Burden of Hypertension: Analysis of Worldwide Data. Lancet, 365, 217-23. http://dx.doi.org/10.1016/S0140-6736(05)70151-3

[3] Mahere, G. (2009) Non-Communicable Diseases in Zimbabwe: An Overview. Ministry of Health and Child Welfare Zimbabwe. (Unpublished).

[4] Matenga, J.A. (2009) Hypertension Lecture Notes. Department of Medicine University of Zimbabwe. (Unpublished).

[5] UNAIDS (2010) Global Report: UNAIDS Global Report on the AIDS Epidemic 2010. Joint Program on HIV/AIDS. UNAIDS 110E/JC195E 20-25.

[6] Smith, C.L., Levy, I., Sabin, C.A., Kaya, E., Johnson, M.A. and Lipman, M.C.I. (2004) Cardiovascular Disease Risk Factors and Antiretroviral Therapy in an HIV-Positive UK Population. HIV Medications, 5, 88-92. http://dx.doi.org/10.1111/j.1468-1293.2004.00191.x

[7] MoHCW (2005) Non Communicable Disease Risk Factors Preliminary Report (Using the WHO STEPwise Approach). Ministry of Health and Child Welfare, Harare.

[8] ZIMSAT (2012) Zimbabwe Demographic and Health Survey 2010-2011. ZIMSTAT, ICF International Inc, Calverton.

[9] US Dept of Health and Human Services (2004) The Seventh Report of the Joint National Committee on Prevention, Detection, Evaluation and Treatment of High Blood Pressure. National High Blood Pressure Education Program.

[10] van der Valk, M., Bisschop, P.H., Romijn, J.A., Ackermans, M.T., Lange, J.M., Endert, E., Reiss, P. and Sauerwein, H.P. (2001) Lipodystrophy in HIV-1-Positive Patients Is Associated with Insulin Resistance in Multiple Metabolic Pathways. AIDS, 15, 2093-2100. http://dx.doi.org/10.1097/00002030-200111090-00004

[11] National AIDS Council. NAC 2011 Annual Report. Accessed 06/05/12. www.nac.org.zw

[12] Apollo, T. (2011) National ART Update. (Unpublished) Ministry of Health and Child Welfare.

[13] Makonde District Health Executive (2012) Makonde District Annual Report 2011. (Unpublished), Ministry of Health and Child Welfare. 
[14] Chow, D., Souza, S., Richmond-Crum, S. and Shikuma, C. (2000) Epidemiologic Evidence of Increasing Blood Pressure in HIV-1 Infected Individuals in the Era of HAART. Antiviral Therapy, 5, S31-S32.

[15] Pinto, A.N. (1996) AIDS and Cerebrovascular Disease. Stroke, 27, 538-543. http://dx.doi.org/10.1161/01.STR.27.3.538

[16] Maggi, P., Serio, G., Epifani, G., Fiorentino, G., Saracino, A., Fico, C., Perilli, F., Lillo, A., Ferraro, S., Gargiulo, M., Chirianni, A., Angarano, G., Regina, G. and Pastore, G. (2000) Premature Lesions of the Carotid Vessels in HIV-1Infected Patients Treated with Protease Inhibitors. AIDS, 14, F123-F128. http://dx.doi.org/10.1097/00002030-200011100-00001

[17] Hewitt, R., Hernandez, F. and Shelton, M. (1999) Systemic Hypertension Associated with Indinavir. Presented at the 39th Inter-Science Conference on Antimicrobial Agents and Chemotherapy, San Francisco, 26-29 September 1999.

[18] Seaberg, E.C., Muñoz, A., Lu, M., Detels, R., Margolick, J.B., Riddler, S.A., Williams, C.M. and Phair, J.P. (2005) Association between Highly Active Antiretroviral Therapy and Hypertensions in a Large Cohort of Men Followed from 1984 to 2003. AIDS, 19, 953-960. http://dx.doi.org/10.1097/01.aids.0000171410.76607.f8

[19] Sattler, F.R., Qian, D., Louie, S., Johnson, D., Briggs, W., DeQuattro, V. and Dube, M.P. (2001) Elevated Blood Pressure in Subjects with Lipodystrophy. AIDS, 15, 2001-2010. http://dx.doi.org/10.1097/00002030-200110190-00013

[20] Lekakis, J., Ikonomidis, I., Palios, J., Tsiodras, S., Karatzis, E., Poulakou, G., Rallidis, L., Antoniadou, A., Panagopoulos, P., Papadopoulos, A., Triantafyllidi, H., Giamarellou, H. and Kremastinos, D.T. (2009) Association of Highly Active Antiretroviral Therapy with Increased Arterial Stiffness in Patients Infected with Human Immunodeficiency Virus. American Journal of Hypertension, 22, 828-834. http://dx.doi.org/10.1038/ajh.2009.90

[21] Addo, J., Smeeth, L. and Lean, D.A. (2007) Hypertension in Sub-Saharan Africa: A Systematic Review. Hypertension, 50, 1012-1018. http://dx.doi.org/10.1161/HYPERTENSIONAHA.107.093336

[22] Hendriks, M.E., Wit, F.W.N.M., Roos, M.T.L., Brewster, L.M., Akande, T.M., de Beer, I.H., Mfinanga, S.G., Kahwa, A.M., Gatongi, P., Van Rooy, G., Janssens, W., Lammers, J., Kramer, B., Bonfrer, I., Gaeb, E., van der Gaag, J., Rinke de Wit, T.F., Lange, J.M.A. and Schultsz, C. (2012) Hypertension in Sub-Saharan Africa: Cross-Sectional Surveys in Four Rural and Urban Communities. PLoS ONE, 7, e32638. http://dx.doi.org/10.1371/journal.pone.0032638

[23] Gwarzo, U., Maji, T., Isa-Dutse, S., Ahmed, Y., Obayagona, K., Okechukwu, E., Odafe, S., Khamofu, H., Torpey, K. and Chabikuli, O. (2012) Cardiovascular Disease Risk Factor Profiles of HIV-Infected Clients: Findings from a Pilot Program to Integrate CVD Screening into HIV Services at a Secondary Health Facility in Kano, North-Western Nigeria. International AIDS Society Conference USA, Abstract MOAE0104.

[24] Diouf, A., Cournil, A., Ba-Fall, K., Ngom-Guèye, N.F., Eymard-Duvernay, S., Ndiaye, I., Batista, G., Guèye, P.M., Bâ, P.S., Taverne, B., Delaporte, E. and Sow, P.S. (2012) Diabetes and Hypertension among Patients Receiving Antiretroviral Treatment since 1998 in Senegal: Prevalence and Associated Factors. ISRN AIDS, 2012, Article ID: 621565. http://dx.doi.org/10.5402/2012/621565

[25] United Nations General Assembly (2011) Political Declaration of the High-Level Meeting of the General Assembly on the Prevention and Control of Non-Communicable Diseases. http://www.who.int/nmh/events/un_ncd_summit2011/en/

[26] Peck, R.N., Shedafa, R., Kalluvya, S., Downs, J.A., Todd, J., Suthanthiran, M., Fitzgerald, D.W. and Kataraihya, J.B. (2014) Hypertension, Kidney Disease, HIV and Antiretroviral Therapy among Tanzanian Adults: A Cross-Sectional Study. BMC Medicine, 12, 125. http://dx.doi.org/10.1186/s12916-014-0125-2

[27] Hejazi, N., Huang, M.S., Lin, K.G. and Choong, L.C. (2014) Hypertension among HIV-Infected Adults Receiving Highly Active Antiretroviral Therapy (HAART) in Malaysia. Global Journal of Health Science, 6, 58-71.

[28] Gazzaruso, C., Bruno, R., Sacchi, P., Fratino, P., Garzaniti, A. and Giordanetti, S. (2003) Hypertension among HIV Patients: Prevalence and Relationships to Insulin Resistance and Metabolic Syndrome. Journal of Hypertension, 21, 1377-1382. http://dx.doi.org/10.1097/00004872-200307000-00028 


\section{Blood Pressure and Anthropometry Measurement Protocol}

Respondents rested for 5 minutes. They were asked to sit in a chair with both feet resting on the floor. A blood pressure cuff circling at least $80 \%$ of the arm would be placed over the left brachial artery with the arm supported on a table at the level of the heart. The cuff would be inflated until the distal radial pulse was no longer palpable and further inflation by $30 \mathrm{mmHg}$ would be done. The diaphragm of a stethoscope was placed over the left brachial artery. Appearance of the first Korotkoff sound (phase I) was used to mark the systolic blood pressure. Disappearance of Korotkoff sounds (phase V) was used to register diastolic blood pressure. Two readings were made, one before the interview and one after 15 minutes, the time it took to administer the questionnaire. If the difference in the diastolic value was $10 \mathrm{mmHg}$ or more between the two readings a third reading was obtained. The final reading was the average of the two readings or the nearest two readings if a third was obtained.

The waist circumference was measured using a dressmaker's tape-measure by measuring the circumference of the torso in the mid-axillary line midway between the last rib and the superior iliac crest. Hip measurement was made by encircling the level of the maximum circumference over the buttocks using a dressmaker's tape-measure. Measurements were rounded off to the nearest $0.1 \mathrm{~cm}$. these were then used to calculate central obesity, i.e. as the proportion of waist circumference to hip circumference [waist-hip ratio (WHR)].

Height was measured with the subject standing upright against a wall on which was affixed a height measuring device. The participant would stand barefoot, back against the wall with heels together and head held in the neutral position. The height would be taken with the participant stretching to the fullest and in exhalation. Measurements were taken to the nearest $0.1 \mathrm{~cm}$.

Weight measurements were taken on pre-calibrated bathroom scales while wearing light clothing and barefoot. Measurements were made to the nearest $0.1 \mathrm{~kg}$. 